\title{
Development Michrosphere Bioadhesive Delivery System from Secondary Metabolit Actynomycetes M10a Rhizosphere Mangrove as Supportive Therapy of Colon Cancer Patients
}

\author{
Fajrin Hasan Basri, Andi Nur Annisa Abbas, Annisa Fitri, Herlina Rante
}

Faculty of Pharmacy, Hasanuddin University, Makassar, Indonesia

\begin{abstract}
Utilization of secondary metabolites from Actynomycetes Mangrove forests can be used as supportive therapy for colon cancer patients that have already through apoptotic testing so it can directly treat the target of illness. This study was prepared in the form of Michrosphere Bioadhesive using secondary metabolite Actynomycetes $\mathrm{M} 10 \mathrm{a}$ rhizosphere mangrove. The purpose of this study was to obtain the development of Michosphere Bioadhesive preparations from secondary metabolites Actynomycetes M10a rhizosphere mangrove as supportive therapy for colon cancer patients. Method of the research is base on Laboratory experiment which started with Purification of Actynomycetes isolate, Secondary Metabolite Fermentation, Michrosphere Bioadhesive Formulation and evaluation of Michrosphere Bioadhesive preparation. The concentration of secondary metabolite Actynomycetes M10a rhizosphere mangrove that been used for each formula are $400 \mu \mathrm{l}, 500 \mu \mathrm{l}$, and $600 \mu \mathrm{l}$, where the percentage of submerged in F1, F2, and F3 are $93,94 \%, 96,96 \%$, and 94 , respectively, $12 \%$. Particular Particle Size Distribution is F1 $(3.1 \mu \mathrm{m})$, F2 $(4.4 \mu \mathrm{m})$, F3 $(3.9 \mu \mathrm{m})$. The rest angles obtained are F1 $\left(0.002^{\circ}\right), F 2\left(0.002^{\circ}\right), F 3\left(0.0016^{\circ}\right)$, respectively. Applied efficiency was obtained by F1 $(214 \mathrm{~nm}), \mathrm{F} 2(210 \mathrm{~nm})$, F3 $(211 \mathrm{~nm})$. Dissolution results show the absorbance results at $266 \mathrm{~nm}$ wavelength. From the results obtained that meet the specifications seen in Formula 2.
\end{abstract}

Article History

Received 13 June 2018

Accepted 15 July 2018

\section{Keyword}

Colon Cancer

Actynomycetes M10a

Rhizosphere mangrove

Michosphere Bioadhesive.

\section{Introduction}

Colon cancer is one of the leading causes of death in both men and women. Patients with colon cancer continue to increase as long as the increasing of smoking habits and bad lifestyle (Gracia, 2011). In Indonesia, colon cancer is included in the third most common cancer attack, after lung cancer and breast cancer. Basic Health Research (Riskesdas) in 2013 states that the prevalence of colon cancer in Indonesia in the productive age population or under 40 years is high enough to reach $30 \%$. Meanwhile, according to data from the American Society Cancer, in 2017 the total new cases of colorectal cancer patients reached 135,430 with an estimated death of 50,260 cases. The main therapies of colorectal cancer include surgery, radiotherapy, and chemotherapy that require a long therapy time 
and great maintenance costs. Although very effective for treating various types of cancer, surgery and radiation are only localized therapies. Most patients have a disease that has spread during diagnosis so that local therapy often fails in eliminating overall cancer (Dipiro, 2009).Through several studies one source of anticancer compounds derived from Actynomycetes.

Actynomycetes is the most antibiotic and anticancer-producing microbial group compared to molds and bacteria especially those from Rhizosphere. Mangrove forests are a highly productive ecosystem, providing important protection for beaches in tidal areas in the tropics and subtropics. The ecosystem of flora and fauna habitats of various marine, freshwater and terrestrial species. Research conducted by (Wang et al., 2011; Xiao et al., 2009) found that the mangrove environment, especially in rhizosphere sediments containing new actinobacteria and streptomyces avicenniae. The bioactive activity of the rhizosphere increases as a result of exudation of compounds produced by plant roots and through the formation of plant hormones (Berg et al,. 2005). (Rante et al., 2016) has isolated actynomycetes M10a from Rhizosphere Mangrove which has activity against colorectal cancer cell WiDr through apoptotic mechanism.

Therefore, innovation development of bioadhesive michrosphere formulation of secondary metabolites is expected to increase colorectal anticancer activity without giving side effects that can damage normal cells and the tendency of drug resistance to patients. Microsphere is a drug delivery system that has advantages among others because of its size is very small (smaller than the size of blood cells) so that it can be given directly orally or through blood tissue directly to the center of the pain. However, this microsphere system is limited because of the short contact time with the absorption area. It is therefore necessary for a system to be in contact for longer with absorption membrane. This development is done through a Microsphere bioadhesive delivery system (Parmar, 2010). Bioadhesive is a drug delivery system that extends the density of live dosage at the application site or extends the absorption time and facilitates the tight contact between the preparation and the absorption surface so as to improve the performance of drug therapy. This causes a longer stay time of drug molecules to tend to high local concentrations. This strategy can be applied to drug delivery systems targeting the colon. Various polymers used for bioadhesive systems are polycarbophils, polyurethanes, polyethylene oxide and polypropylene oxide (Parmar, 2010).This study aims to develop a bioengineous michrosphere formula from secondary metabolite actynomycetes M10a Rhizosphere Mangrove anticancer as supportive for colon cancer patients.

\section{Materials and Methods}

\section{Equipment and Materials}

The tools used are horn spoons, stirring rods, basins, porcelain cups, parchment paper, scissors, watch glasses, erlenmeyer flasks, measuring cups, pumpkin shapes, beaker, $\mathrm{pH}$ meters, rotary evaporators, ovens, analytical scales, microsphere size analyzer, UVVisible spectrophotometer, glass preparation, dissolution tool, spoit, and viscometer. The ingredients used are Actynomycetes Isolate, aquadest, Acetic Acid, 96\% ethanol, polycarbophyls, paraffin liquid, span 80 , petroleum ether, cyanoacrylic glue, rat, tissue, gloves, Spectrophotometric Uv-Vis, aluminum foil, Whatmann no. 1 and No. 44, silica gel, plastic wrap, and mask. 


\section{Research Prosedures}

\section{The Process of Rejuvenating Actynomycetes Bacteria}

Actynomycetes isolates were grown into sna medium (starch nitrate agar). As much as 1 ose isolate actynomycetes from new medium sna kemedium until obtained pure isolate, and then incubated for 24 hours.

\section{Fermentation (production of metabolite compounds)}

The isolate obtained was transferred to the starter kemedium then transferred to a $500 \mathrm{ml}$ erlenmeyer containing $100 \mathrm{ml}$ of the same medium. Fermentation was carried out at $280 \mathrm{c}$ for 11 days under the conditions of the teragity at a rate of $150 \mathrm{rpm}$.

3. Formulation and Evaluation of Biooadhesive Microsphere

\begin{tabular}{ccccc}
\hline \multirow{2}{*}{ No. } & Equipment & \multicolumn{3}{c}{ Formula } \\
\cline { 3 - 5 } & & F1 & F2 & F3 \\
\hline 1. & Metabolite Sekunder & $400 \mu \mathrm{l}$ & $500 \mu \mathrm{l}$ & $600 \mu \mathrm{l}$ \\
2. & Actynomycetes & $2 \mathrm{~g}$ & $2 \mathrm{~g}$ & $2 \mathrm{~g}$ \\
3. & Ethyl Cellulose & $20 \mathrm{ml}$ & $20 \mathrm{ml}$ & $20 \mathrm{ml}$ \\
4. & Aseton & $1,5 \mathrm{~g}$ & $1,5 \mathrm{~g}$ & $1,5 \mathrm{~g}$ \\
5. & Span 80 & $100 \mathrm{ml}$ & $100 \mathrm{ml}$ & $100 \mathrm{ml}$ \\
\hline
\end{tabular}

Used Actynomycetes bacteria, then mixed with ethyl cellulose that has been dissolved with acetone to form a mixture A. Separately mixed liquid paraffin with span 80 then homogenized for 10 minutes and formed a mixture of $B$. After that, mixed $A$ to $a$ mixture of $B$ while being sensed at $2500 \mathrm{rpm}$ for 30 minutes. The final mixture is filtered using a filter paper, and the formed microsphere is washed with n-hexane until it is nongreasy.

4. Evaluation of Microsphere Bioadhesive (Pendyala, yamini. 2012)

a. Testing the particle size distribution

Observed microsphere under an optical microscope then calculated the particle size of the microsphere.

b. Determination of Break Angle

The rest angle is determined by inserting the michrosphere sample into a funnel that has been covered in the bottom, then flattening the surface of the sample. Place the semilog paper just below the funnel. Then the funnel cap is opened, recorded and calculated the break angle of each formula by the following formula

c. Determination of Percent Rendamen

The microsphere obtained from each formula is weighed, then calculated percent of rendamen by considering the weight of the active ingredient and the polymer by using the following formula:

$\%$ Rendament $=$ (practice weight) / (theory weight) $\times 100 \%$

d. Applied Efficiency

A sample of $50 \mathrm{mg}$ was dissolved with artificial intestinal fluid with a $\mathrm{pH} \pm 8$ then filtered and measured its wavelength according to the standard.

e. In-vitro Wash-off Test

Testing In-vitro wash off Test is done by using organs of animal intestine try the mice (Mus musculus) which I then used the intestinal organs to see the bioadhesive michrosphere can be attached to the intestinal organs. 
f. In-vitro Dissolution Test

Dissolution test using basket method at $37 \pm 0.50 \mathrm{C}$ with rotation speed $100 \mathrm{rpm}$ using PH 8 Posfat buffer as dissolution medium. Samples of the microsphere $100 \mathrm{mg}$ were used in this test. Samples samples are periodically taken over a period of time and analyzed by spectrophotometric method.

\section{Results and discussion}

After extracting the Actynomicetes isolate, a microsphere bioadhesive formulation was obtained by percent rendamen for each of the formulas, 93.94\% (F1), 96.96\% (F2), and 94.12\% (F3).From the measurement of the particle size distribution, it was found that there was no significant difference of the three tested formulas. The mean particle diameter of F1 $(3.1 \mu \mathrm{m}), \mathrm{F} 2(4.4 \mu \mathrm{m})$, and F3 $(3.9 \mu \mathrm{m})$. These results indicate that the concentration of secondary metabolites Actynomicetes does not affect the resulting formula in which of the three formulas and all form in microspheres. The particle size distribution graph of F2 can be seen in figure 1.

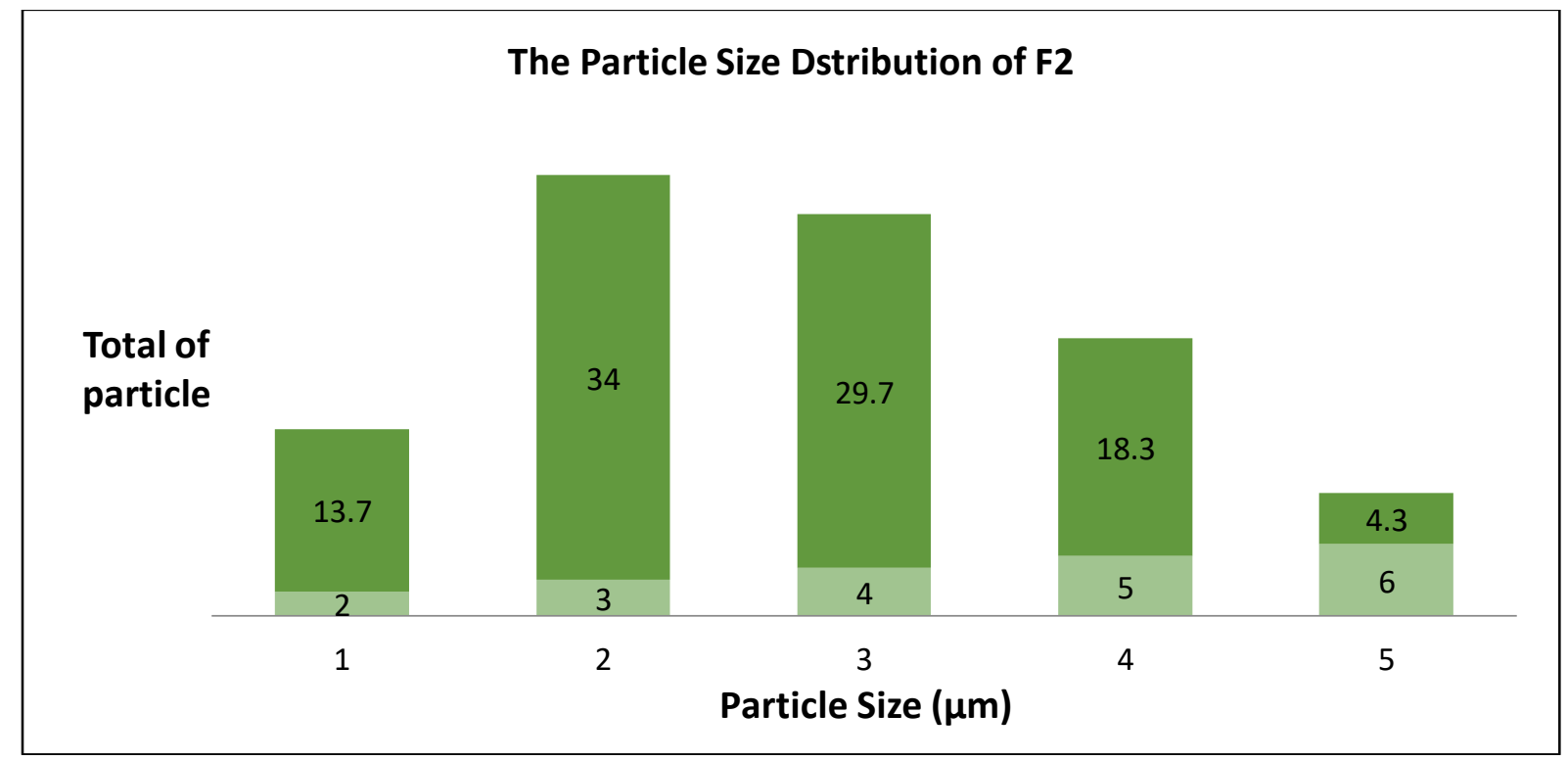

Particle size that shown in F2

Cumulative percentage of particle size

Figure 1: Particle size distribution

Based on the graph, the higher cumulative percentage is $34 \%$ in $3 \mu \mathrm{m}$ particle size. That means most of particle size that found in F2 has $3 \mu \mathrm{m}$. The smallest particle shown the good form of microsphere that have been prepared.

On the measurement of the velocity of flow and the rest angle, the flow rate is 0.105 $\mathrm{g} / \mathrm{s}(\mathrm{F} 1), 0.064 \mathrm{~g} / \mathrm{s}(\mathrm{F} 2), 0.095 \mathrm{~g} / \mathrm{s}(\mathrm{F} 3)$ and the fixed angle is $0.002^{\circ}(\mathrm{F} 1), 0.002^{\circ}$ (F2), and $0,0016^{\circ}(\mathrm{F} 3)$. A silent angle below $25^{\circ}$ represents a good flow rate so it is predicted to produce a good release rate of the drug when formulated. Maximum wavelength determination results show that the highest uptake of the formula with in vitro gastric medium without enzim is at $266 \mathrm{~nm}$ wavelength. Of the three formulas showed insignificants rate of dissolution. Further measurements were made on each of the formulas which obtained the highest absorbance of F1 $(214 \mathrm{~nm}), \mathrm{F} 2(210 \mathrm{~nm}), \mathrm{F} 3(211 \mathrm{~nm})$. In the 
formula 2 the highest absorbance is at $210 \mathrm{~nm}$ wavelength indicates the same wavelength as the references so that shown $100 \%$ absorption efficiency is found in formula 2 . The spectrophotometric graph is shown in Figure 2.

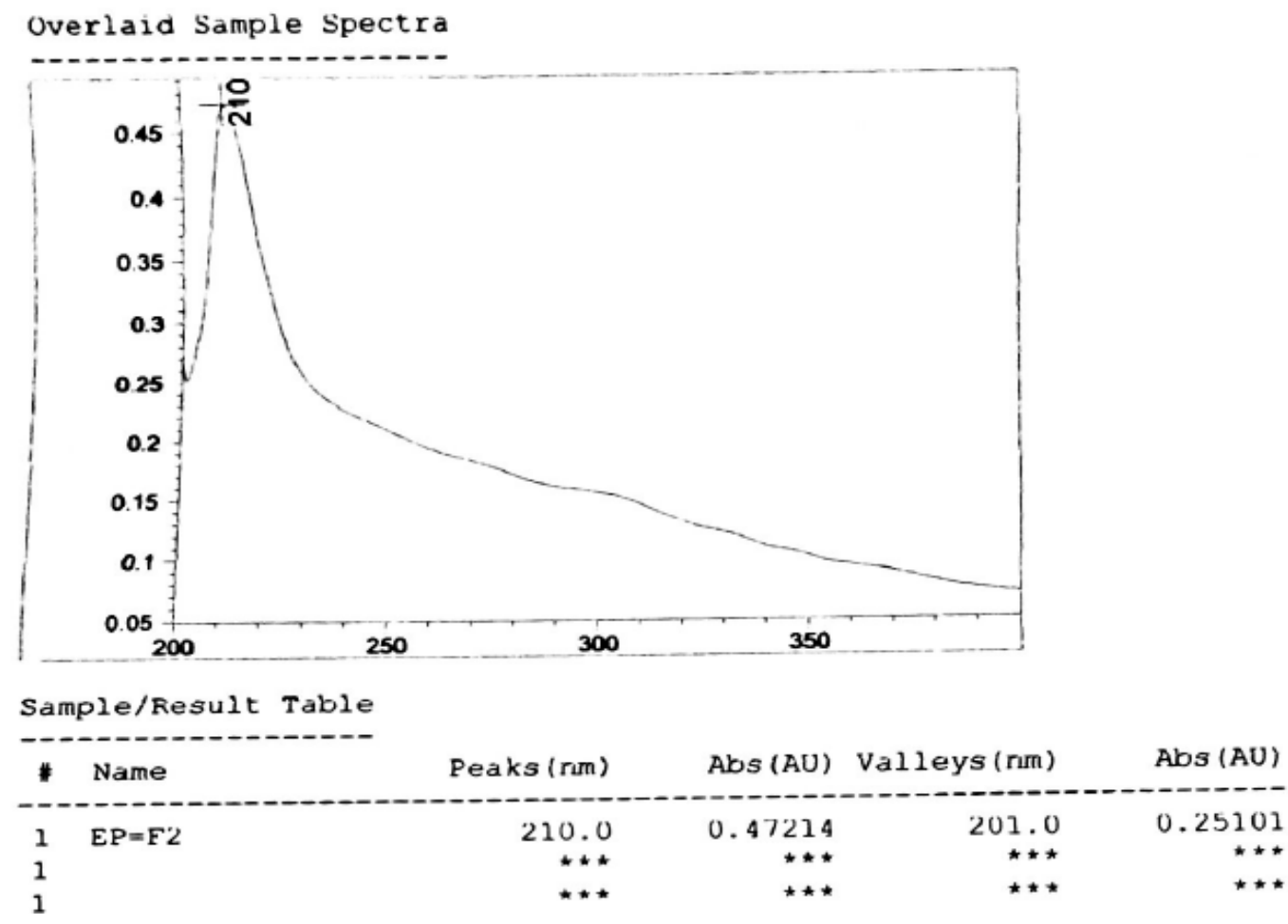

Figure 2. Applied Efficiency of F2

Bioadhesive capability is also tested in microsphere bioadhesive formula. In vitro wash test was performed by orally administered in mice (Mus musculus). Method that used is to indicate the microshphere attached to the intestine so it was predicted that the bioadhesive properties were obtained in all three formulas.

\section{Conclusions}

The results obtained by using secondary metabolite Actynomycetes M10a are $400 \mu \mathrm{l}$, $500 \mu \mathrm{l}$, and $600 \mu \mathrm{l}$, respectively, where the percentage of rendamen in F1, F2, and F3 are 93,94\%, 96,96\%, and 94, respectively, 12\%. Particular Particle Size Distribution is F1 (3.1 $\mu \mathrm{m})$, F2 $(4.4 \mu \mathrm{m}), \mathrm{F} 3(3.9 \mu \mathrm{m})$. The rest angles obtained are F1 $(0.0020), \mathrm{F} 2(0.0020), \mathrm{F} 3$ $(0.00160)$, respectively. Applied efficiency was obtained by F1 $(214 \mathrm{~nm}), \mathrm{F} 2(210 \mathrm{~nm}), \mathrm{F} 3$ $(211 \mathrm{~nm})$. The dissolution results showed absorbance results at $266 \mathrm{~nm}$ wavelengths. While for invitro wash off test result using Mucus organs organ (Mus musculus) it was found that the Microsphere bioadhesive preparation could be attached to the intestinal organ of mouse. Based on the evalution results, F2 is the good formula of Microspher bioadhesiveActynomycetes M10a Rhizosphere mangrove.

\section{Acknowledgment}

This research was supported by Pharmacy faculty of Hasanuddin University, funded by The Ministry of Research Technology and Higher Education. 


\section{References}

Arora, A., Nair., M.G. \& Strasburg, G.M. 1998. Structure-Activity Relationshipsfor Antioxidant Activities of a Series of Flavonoids in a Liposomal System.Free Radic. Biol. \& Med., 24(9): 1355-1363.

Alteri, R., Priti Bandi, MS; Durado Brooks, MD, MPH; Vilma Cokkinides, PhD, MSPH; Mary Doroshenk; Ted Gansler, MD; Keona Graves; Eric Jacobs, PhD; Debbie Kirkland; Joan Kramer, MD; Bernard Levin, MD; Adriane Magro; Marji McCullough, ScD, RD; Deepa Naishadham, MS; Brenda McNeal; Mona Shah, MPH; Scott Simpson; Robert Smith, PhD; Kristen Sullivan, MS, MPH; Dana Wagner. 2011. Colorectal Cancer Facts \& Figure 20112013. Atlanta:American Cancer Society.

Balaji, S. M. 2009. Textbook of Oral and Maxillofacial Surgery. Elsevier, New Delhi.

Berg, et. Al. 2005. The Rhizosphere as a Reservoir for Opportunistic Human Pathogenic Bacteria. Environmental microbiology. 7(11):1673-85

De Vita, Vincent, T., Hellman, Rosemberg, S. \& Steven, A.2011. CancerPrincipies \& Practice of oncology, $9^{\text {th }}$ Lippincott Williams \& Wilkins.

Dipiro, J.T. 2009.Pharmacoterapy Handbook 7th edition. Mc Graw Hill, New York.

El-Hady, H.H.A., Daboor,S.M. \&Ghoniemy, A.E. 2007. Nutritive Andantimicrobial Profles of some Seagrass from Bardawil Lake. Egyptian J.Aq. Research, 33:103-110.

Gracia J. Win time. 2011. The Role Of Dietary Fiber In Prevention Of Cancer Colorectal. Faculty of Medicine University Kristen Krida Wacana

Henra, R., Ahmad, S., Oskoueian, Sukari, A., Shukor, M.Y. 2011. Antioxidant, antiinflammatory andcytotoxicity of Phaleria macrocarpa (Boerl.) scheff fruit. $B M C$ Complementary and Alternative Medicine. 11: 110-119.

Parmar, H., Bakliwal, S., Gujarathi, N., Rane, B. \& Pawar, S. 2010. Different Methods of Formulation and Evaluation of Mucoadhesive Microsphere. International Journal of Applied Biology and Pharmaceutical Technology.1(3): 1157-1167.

Pendyala, Yamini \&Talasila, S. 2012. Formulation And Evaluation OfBioadhesive Microsphere Of Ramipril.International Journal of Pharmaceutical and Chemical Sciences. 1(3): 2277-5005.

Rante, Herlina., habibie., aminullah., \& fatmawati, aisyah. 2016. Determination Of Potency Apoptosis Induction Of Secondary Metabolite Actinomycetes From Mangrove Rizosphere Using Flow Cytometry Method. Faculty Of Pharmacy. Hasanuddin University

Saija, A., Scalese, M., Lanza, M., Marzullo, D, Bonina, F \& Casteli, F. 1995. Flavonoids as Antioxidant Agents: Importance of Theirlnteraction with Biomembranes.Free Radic. Biol. \& Med. 19(4):481-486.

Wang Rong., John A. Dearing., Peter G. Langdon., Enlou, Zhang., Xiangdong, yang., Vasilis, dakos., \& Marten, Schefer. 2011. Growth propagation of yeast in linear arrays of microfluidic chambers over many generations. Biomicrofluidics 5(4):44118-441189

Xiao J., Chen XW., Davies BA., Saltiel AR., Katzmann DJ., \& Xu Z. 2009. Structural basis of Ist1 function and Ist1-Did2 interaction in the multivesicular body pathway and cytokinesis. Mol Biol Cell 20(15):3514-3524 